\title{
Sustainability of nuclear energy with regard to decommissioning and waste management
}

\author{
S. Lindskog ${ }^{1}$, R. Sjöblom ${ }^{2} \&$ B. Labor ${ }^{3}$ \\ ${ }^{1}$ The Swedish Radiation Safety Authority, Sweden \\ ${ }^{2}$ Tekedo AB, Sweden \\ ${ }^{3}$ Badania Dydaktyczne, Poland
}

\begin{abstract}
The paper analyses the sustainability aspects of nuclear power with regard to environmental liabilities associated with decommissioning of nuclear facilities and with waste management.

Sustainability is defined and literature on evaluation of sustainability in the nuclear and coal energy fields is reviewed. It is found that the results are incoherent and that methodologies for evaluations are needed as well as adequately structured knowledge bases. Examples of such tools and work are presented from the perspective of the Swedish Radiation Safety Authority.

Different aspects of nuclear energy sustainability are reviewed and summarized, and it is found that appropriate management of the nuclear liability associated with protection of health and the environment - now and in the future - is a necessary prerequisite in order for nuclear power to qualify as sustainable.

Analyses in a historical perspective show that sustainability awareness has been around for at least as long as agriculture, and that some shortcomings are actually modern inventions. The analyses also show that sustainability awareness may appear as trends and that comprehensive perspectives are essential.

Planning for decommissioning and the estimation of associated costs have proven to be treacherous exercises. Moreover, the timing of the planning must be based on the need for appropriate finance so that adequate funds are available at the time when they are needed. It is the duty of our generation to assess what is adequate and to find responsible solutions. But we should also ask the next generation and carefully consider the perspective that they provide to us.

Keywords: sustainability, nuclear, liability, segregated fund, cost calculation, younger stakeholders.
\end{abstract}




\section{Background, purpose and scope}

\subsection{Nuclear liability evaluation and financing in Sweden}

Generally, it is not forbidden by law for natural persons and other private legal entities to perform activities that have a potential for causing detriment to health and environment. Instead, it is the risk for such detriment that is being regulated in various legislations and that is also overseen by various Authorities.

Thus, in Sweden, it is the task of the Swedish Radiation Safety Authority (SSM), (Swedish name Strålsäkerhetsmyndigheten) to oversee radiation protection, under The Radiation Protection Act [1], and nuclear activities, under the Act on Nuclear Activities [2]). The oversight covers all kinds of such activities, including nuclear electric power generation.

Similarly, SSM also oversees the planning for the final storage of the nuclear waste, the planning for the decommissioning of nuclear facilities and the system for financing the associated future costs. This financial oversight is carried out under the Nuclear Liability Act [3] which stipulates that plans and cost calculations shall be submitted to SSM each year for nuclear power plants and every third year for other facilities.

For nuclear power plants, there are two "compartments" for securities and fees to segregated funds managed by the Government:

A the anticipated costs for decommissioning and waste management etc., and

B a risk fee intended to cover the residual risk that the Government takes in its management and as ultimate guardian of the fund system.

Compartment A comprises a combination of securities (unlimited in time) and assets in segregated funds. Securities are lifted at the same pace as that of the payments that flow into the segregated funds.

In addition, securities must be provided to cover "unplanned events".

It is the owners and operators of the nuclear facilities that carry the full responsibility for protecting health and the environment. They also have the full responsibility to ensure that adequate funding is available at the time when it is needed for any associated liabilities. The role of SSM and other Authorities is to instigate such work and to ensure that those eligible fulfil all their obligations.

Most of the nuclear liabilities are associated with our 12 modern nuclear power plants, 10 of which are presently in operation. But more than $10 \%$ of the total estimated decommissioning liabilities are associated with old nuclear technology development facilities.

There are considerable obstacles and pitfalls related to the planning and associated cost estimates, especially for old facilities. It is therefore a daunting and demanding task for owners and operators to comply with the requirements on financial planning. Similarly, the SSM needs a good knowledge base for its oversight, and accordingly, it is also the duty of the SSM to carry out and to commission relevant research work [4]. Recent publications include References [5-14]. 


\subsection{Purpose and scope}

The purpose of the present paper is to analyse the sustainability aspects of nuclear power with regard to environmental liabilities associated with decommissioning of nuclear facilities and with waste management.

The objective is to contribute to the knowledge base needed for assessments of sustainability for nuclear power in general and for comparisons between different sources of energy. The objective is also to illustrate how environmental liabilities can be managed for different energy systems and in different fields of technology.

\section{Sustainability and associated methodologies for analysis and comparison}

\subsection{Sustainability definitions}

According to the Brundtland report [15] from 1987, sustainable development can be defined as follows:

"Sustainable development is development that meets the needs of the present without compromising the ability of future generations to meet their own needs. It contains within it two key concepts:

- the concept of 'needs', in particular the essential needs of the world's poor, to which overriding priority should be given; and

- the idea of limitations imposed by the state of technology and social organization on the environment's ability to meet present and future needs."

This principle of sustainable development is closely associated with the polluter pays principle (PPP). It is also dealt with in the Brundtland report [15] which in this case refers to an OECD decision from 1972 [16]. A corollary to the polluter pays principle is the principle of equity between generations.

\subsection{The need for tools and knowledge bases for assessments}

It might be tempting to assume that the above quoted basic principles might be readily applied to various industrial activities including energy production. However, the conclusions reached are not entirely coherent.

For instance, the World Nuclear Association concludes the following [17]:

"Our confidence that nuclear power is a 'sustainable development' technology because its fuel will be available for multiple centuries, its safety record is superior among major energy sources, its consumption causes virtually no pollution, its use preserves valuable fossil resources for future generations, its costs are competitive and still declining, and its waste can be securely managed over the long-term".

Similar conclusions, albeit expressed somewhat more moderately, can be found in a report [18] from the OECD/NEA. 
The conclusion above "that the waste can be securely managed" should not be interpreted to imply that systems are in place for final disposal of all nuclear waste in all countries. In fact, no country has yet commissioned a repository for civilian spent nuclear fuel or high level waste from reprocessing of such fuel.

The coal combustion community considers [19] three pillars of sustainable development: "economic prosperity, social well-being and environmental sustainability", (cf the Brundtland report above) and makes the following observations:

- Coal will play an important role in energy systems that support sustainable development for the foreseeable future.

- Further improvement in coal's environmental performance will be required ... to reduce greenhouse gas emissions. ..."

Of course, carbon capture (carbon dioxide sequestration) is still at the development stage.

It can be concluded that the application of the fundamental principles of sustainability is not straightforward. Tools for assessment and comparison are needed as well a knowledge bases structured in a feasible manner.

\subsection{Tools for assessment and need for appropriately structured knowledge}

Modern tools for assessment of the functioning of industrial facilities have largely been developed in conjunction with the planning and safe operation of advanced industrial facilities, especially in the chemical and nuclear industries, and examples include References [20-23].

General considerations in such analyses include the following:

- definition of the system, including what is prerequisites (outside the system) and what is inside

- $\quad$ identification and description of features, events and processes

- $\quad$ identification and studies of scenarios

- comparison (e.g., for best available technology) based on comparing one type of characteristic at the time, and to make overall assessment thereafter.

The Swedish research on nuclear waste disposal and associated planning, including financial planning, was inaugurated in the $1970 \mathrm{~s}$, and have since then been rather intensive in industry (the major effort) as well as at the Swedish Radiation Safety Authority (SSM) and its predecessors. An overview of objectives and direction of the Authority work can be found in Norrby [4], see also References [24-29].

Lessons learned from the SSM work include that assessments and comparisons is a topic in itself, and requires substantial efforts. Pitfalls are numerous, and structured approaches are essential. Critical areas include integration between disciplines and awareness of the sociological, financial and legal dimensions. Perspective on time is also important, including difficulties in making prognoses for chemical developments, awareness of all different relevant issues - which may change considerably with time - and the general level of scientific and technical knowledge which is being elevated all the time. 


\section{Nuclear energy sustainability}

\subsection{Availability of uranium and the efficiency in its utilization}

All contemporary nuclear power reactors use uranium based nuclear fuel. Uranium ore typically contains levels of uranium at a fraction of a percent or lower. This implies that most of the ore becomes tailings that may emit radioactive radon to the surrounding air, and various elements in the periodic table to the groundwater. Thus, remediation and reclamation are needed.

Reference [30] states that the total identified sources of uranium are sufficient to last for more than 100 years at the present level of consumption. The report also states that the deployment of advanced reactor and fuel cycle technologies could conceivably extend the long-term availability of uranium to thousands of years.

\subsection{Protection of health and the environment}

Most of the potential for detriment to health and the environment from nuclear power generation originates from radiation. The radionuclides emitting the radiation may be natural or artificial. (A nuclide is a specific combination of elementary particles in the nucleus of an atom). Large amounts of artificial radionuclides are formed in a nuclear reactor. They give rise to radiation during short (very intensive) and long (less intensive) time. Different types of radiation have very different absorption characteristics.

So far, doses in Sweden have been kept well within limits for the very most part. In particular, doses to the public have been very far below the limits. We have also been fortunate in that radiological consequences of deviations from normal operating conditions have been insignificant.

Accidents do occur, however, as is illustrated by the Chernobyl disaster which affected Sweden by fall-out [31]. This particular type of accident is not technically possible with our designs of reactors. Nonetheless, it is an appropriate attitude from a safety point of view not to discard the possibilities of accidents.

Decommissioning of a nuclear facility typically costs at least a couple of orders of magnitude more than the demolition of a corresponding non-nuclear facility. The reason for this is the presence and properties of the remaining radionuclides, c.f. the description above. Moreover, the waste from decommissioning will have to be deposited, typically - and in the case of Sweden - together with other waste that has been kept in interim storage. However, according to present domestic plans, the spent nuclear fuel will be deposited in a separate facility.

This constitutes an environmental liability that has to be appropriately managed in terms of technical and financial planning, see and compare with Section 1.1 above. Such appropriate management is an essential prerequisite for nuclear energy to qualify as sustainable. 


\section{Results from information searches and analyses}

\subsection{Historical perspective}

Sustainability awareness is often thought of as a modern phenomenon, but is actually likely to be at least as old as agriculture. Our forefathers freed their farmlands from stones and put them in walls to protect the crops from grazing animals. This example illustrates a strong solidarity with descendants.

The greenhouse effect has been known for more than 100 years, not only as some curiosity in exotic scientific literature, but also in popular and well circulated literature in which it was put forward in 1919 by the Swedish scientist Svante Arrhenius [32] as more or less a matter of course. It was pointed out as just about the only mechanism by means of which mankind might achieve an increase in world temperature. He also calculated that the carbon dioxide reserves in the atmosphere would last for only about 37 years should it not be replenished by microbial activity and coal combustion.

It is appropriate to wonder why the issue of global warming was laying dormant for about a century, and then relatively recently and suddenly became a major issue. This raises the question of what other important issues might escape contemporary attention only to become major issues tomorrow.

The book by Arrhenius [32] deals rather extensively with the issues of sustainability of mineral and energy resources, and it ends with emphasizing the need for recycling and the exhort: "thou shalt not waste".

Another example of what might be referred to as a "marination effect" concerns the awareness of the significance of man-made radionuclides. It took a few decades after x-rays had been discovered and put to use in hospitals in the 1890s until the health problem of induced cancers became recognized and dealt with. Preparation of man-made radionuclides on a large scale was inaugurated in 1942 when the first nuclear reactor was started, but it took until the 1970s until the problems with the nuclear waste became fully recognized.

A similar but less transient development of awareness is taking place since about 20 years on the issue of decommissioning of nuclear facilities. Examples of recent work are presented in the subsequent sections 4.2 and 5 .

\subsection{Environmental liabilities and the polluter pays principle}

Background to this section in the form of previous publications by the present authors can be found in References [5-14].

The polluter pays principle has been implemented in the Swedish Environmental code [33] as follows: "Persons who pursue or have pursued an activity or taken a measure that causes damage or detriment to the environment shall be responsible, until such time as the damage or detriment ceases, for remedying it to the extent deemed reasonable ...". Since there is no limit in time, a liability will exist as long as remediation has not been completed.

It was mentioned in Section 1.1 that for nuclear liabilities, financial resources are generally accumulated in segregated funds so that funding will be available at 
the time when it is needed. The funding should be sufficient but not superfluous. A prerequisite for the functioning of such a system is that future costs can be estimated with sufficient precision. There are numerous examples of deviations in this regard, and consequently a structured approach is warranted.

At least for private enterprises, the nuclear [3] as well as the financial [34-37] legislations require that liabilities be calculated with a high or even very high precision. The harshest punishment (prison) might come about as a consequence of the penal law [38] in cases where the financial reporting is grossly misleading.

Such deviation might actually not be very far fledged since it has proven recurrently difficult to make precise cost estimations for decommissioning, especially for old research facilities. A good advice is therefore to follow - or at least carefully check - existing standards [39-40], and to conscientiously declare any remaining uncertainties together with the reasons why they still exist. What is just said implies that the timing of the planning for decommissioning is dictated by the needs of the financial planning.

\section{Results from field studies}

Sustainability is about the future, and about whether people in the future will experience an improved or a depleted basis for their existence. Of course, we cannot ask them, and consequently we have to rely on the adequacy of our own preferences.

There is, however, a possibility to get some information on the issue by asking people that are young today since they constitute the next generation. This is not often done however, since surveys typically are carried out via paper forms that are sent out by ordinary mail. Since young people today communicate by other means, the response rates are typically insufficiently low.

Consequently, the approach chosen in the present work comprises personal interviews of 1444 persons attending secondary grammar school (High School/Gymnasium) and the response rate achieved is close to $100 \%$. (The first stage of the present work has been reported in [6, 7]). The interviews were carried out during late 2007-2010 in the towns Gdansk, Lublin, Elblag and Jaworzno (Katowice) in Poland and Trnava in Slovakia. No difference was found between the genders. Also no difference was found between the towns in spite of the fact that Jaworzno is a coal mining town that is surrounded with coal condensation power plants, and the town of Trnava is close to the nuclear power reactors on the Bouniche site. Two of these reactors have been shut down permanently, and are thus in the transition phase for decommissioning, and the others are still in operation.

It was found that the young people in the study have the following preferences:

1 Truly sustainable sources of energy are preferred. Coal has the lowest score.

2 Sweden should take care of its own waste.

3 Only few people can consider having a final disposal of nuclear waste near to their homes. 
4 Protection of health and environment are most important for final disposal, but distance from home is also an important consideration.

5 Young people feel that unease with the risks together with lack of knowledge are the most important aspects for acceptance of nuclear waste disposal while trust for the stakeholders involved and local opportunities are less important.

A brief compilation of the actual answers are as follows (the full data will be published later):

Question 1. Which form of energy do you prefer?

\begin{tabular}{|c|c|c|}
\hline Coal & 4,4 & Windmills \\
\hline Nuclear Power & 24,7 & Miscellaneous \\
\hline Hydropower & 31,8 & \\
\hline
\end{tabular}

Question 2. Who shall take care of the Swedish waste?

Sweden

$88,1 \quad$ Other countries

11,9

Question 3. Can you consider having a site for final disposal of nuclear waste near to your home?

Yes

15,6 No

Question 4. What is your opinion towards a site for final disposal of nuclear waste?

In favour

Against

24,3

Indifferent

25,5

Question 5. Which aspect is in your opinion most crucial for the acceptance of a final disposal?

Safety aspect

Environmental aspect $\ldots \ldots \ldots \ldots . . . . . . . . .27,8$
Location aspect, as far

Location aspect, as far

Methods and techniques ........... 8,6

from home as possible

21,2

Economic growth ..................... 3,2

Miscellaneous ......................... 0,8

Question 6. Which of these values do you base your opinion upon?

Trust for the stakeholders

Lack of knowledge

involved 11,5

Unease with the risks

Opportunities linked to a

Miscellaneous

disposal for nuclear waste

10,1

\section{Concluding remarks}

The definitions of sustainability are quite clear. Analyses have nonetheless been carried out in different ways in different areas of technology, and the results are not coherent. Consequently, methodologies are needed that enable comparisons to be carried out in a more uniform and systematic manner. This requires that appropriately structured knowledge bases be established together with efficient modes for communication and knowledge transfer.

The sustainability of nuclear energy is not just a matter of availability of uranium and efficiency in its utilization. Protection of health and the environment - now and in the future - is a necessary prerequisite in this regard. The protection in the future must be carried out in full compliance with the polluter pays principle. It is not necessarily required that the generation that 
benefits from the nuclear electricity also actually carries out the decommissioning of the nuclear facilities and disposes permanently of all the waste. There may be good technical reasons to operate nuclear facilities for the optimum lengths of time, and this may imply times longer than one generation. It is essential, however, that the benefitting generation leaves behind the full technical solutions together with all the financial resources needed for adequate protection of health and the environment. So far, and in the case of Sweden, this has meant green field conditions.

The historical compilation shows that sustainability awareness may well appear in the form of trends. This calls for comprehensive and systematic approaches based on appropriately structured knowledge bases.

It is a natural element of human nature as well as human culture to care about the offspring, and to leave behind a better basis for existence. Forces that counteract this may include exaggerated emphasis on quarterly reports by institutional investors. The concern for descendants is not unconditional, however. Research suggests that an individual will sacrifice consumption to benefit future generations only if a guarantee exists that others will do the same [41]. Thus, bodies are required as ombudsmen for the public to ensure general compliance. Such solutions are proposed in [41].

Planning for decommissioning and the estimation of associated costs have proven to be treacherous. Careful analyses are needed in order to obtain the precision required. This includes radiological surveying, selection of techniques to be used and identification and evaluation of potential cost raisers. It also includes comparison with already completed projects. The timing of such evaluations is dictated by the needs for financial planning, and this may imply that it must be carried out many years, perhaps decades, before the plans may be needed for purely technical reasons.

It is the duty of our generation to assess what is adequate and to find responsible solutions, and in this sense we must act as ombudsmen for the future generations. We do, however, have access to the next generation. It is therefore imperative that we learn about their values and carefully consider what they share with us. It is probably safe to assume that the perspectives and requirements will be different in the future, and we should strive for solutions that have good prognoses for standing the ultimate tests of time. For instance, it is only forty years since Sweden participated in a sea-dumping campaign that was carried out under the auspices of the United Nations. Such a practice is far from acceptable today.

In this perspective, it is of crucial importance to include stakeholders in general and younger stakeholders in particular, in knowledge transfer and dialogue. It is also important that information is passed on to future generations. It is imperative that this process is supported by society e.g. in terms of funding of financial resources and information about nuclear waste liabilities.

\section{References}

[1] Radiation Protection Act. (In Swedish: Strålskyddslag). SFS 1988:220. 
[2] Act on Nuclear Activities. (In Swedish: Lag om kärnteknisk verksamhet). SFS 1984:3.

[3] Nuclear Liability act. (In Swedish: Lag om finansiella åtgärder för hanteringen av restprodukter från kärnteknisk verksamhet). SFS 2006:647.

[4] Norrby, S., A Regulatory Authority's Needs for R\&D to Develop Competence in Assessing Nuclear Waste Management Safety. Scientific Basis for Nuclear Waste Management XXI, edited by Ian G. McKinley, Charles McCombie (Mater. Res. Soc. Symp. Proc. Vol. 506, Warrendale, PA, 1997).

[5] Lindskog, S. \& Sjöblom, R., Implementation of the polluter pays principle example of planning for decommissioning. Environmental Economics and Investment Assessment III, 3-5 May 2008, Limassol, Cyprus. WIT Transactions on Ecology and the Environment, Vol 131. Wit Press, 2010. ISBN 978-1-84564-436-9.

[6] Labor, B. \& Lindskog, S., Values held by young stakeholders on financial planning regarding liabilities for nuclear decommissioning. Environmental Economics and Investment Assessment III, 3-5 May 2008, Limassol, Cyprus. WIT Transactions on Ecology and the Environment, Vol 131. Wit Press, 2010. ISBN 978-1-84564-436-9.

[7] Tyszkiewicz, B. and Labor, B., A Survey of Younger Citizens Values towards Decommissioning and Dismantling of Older Nuclear Facilities in a European Perspective. SKI* Report 2008:52. June, 2008.

[8] Lindskog, S. \& Sjöblom, R., Radiological, technical and financial planning for decommissioning of small nuclear facilities in Sweden. Proceedings of the 12th International Conference on Environmental Remediation and Radioactive Waste Management, ICEM2009, October 11-15, 2009, Liverpool, UK.

[9] Lindskog, S., Cato, A. \& Sjöblom, R., Estimations of costs for dismantling, decommissioning and associated waste management of nuclear facilities, and associated impact on decision processes, functioning of markets and the distribution of responsibilities between generations. Environmental Economics II, 28-30 May 2008, Cadiz, Spain. WIT Transactions on Ecology and the Environment, Vol 108. Wit Press, 2008. ISBN 978-184564-112-2.

[10] Lindskog, S. \& Sjöblom, R., Regulation evolution in Sweden with emphasis on financial aspects of decommissioning. Decommissioning Challenges: an Industrial Reality? Sept. 28 to Oct.2, 2008 - Avignon, France.

[11] Iversen, K., Salmenhaara, S., Backe, S., Cato, A., Lindskog, S., Callander, C., Efraimsson, H., Andersson, I. \& R. Sjöblom, R., Cost calculations at early stages of nuclear facilities in the Nordic Countries. The 11th International Conference on Environmental Remediation and Radioactive Waste Management. September 2-6, 2007, Bruges (Brugge), Belgium.

[12] Cato, A., Lindskog, S. \& Sjöblom, R., Financial Planning as a Tool for Efficient and Timely Decommissioning of Nuclear Research Facilities. American Nuclear Society. Decommissioning, Decontamination and 
Reutilization. Capturing Decommissioning Lessons Learned. September 16-19, 2007, Chattanooga, Tennessee, USA.

[13] Sjöblom, R., Sjöö, C., Lindskog, S. \& Cato, A., Early stage cost calculations for determination and decommissioning of nuclear research facilities. The 10th International Conference on Environmental Remediation and Radioactive Waste Management. Glasgow, UK, 4-8 September, 2005.

[14] Laraia, M. \& McIntyre, P. J., responsible officers; Cato, A., Lindskog, S. \& Sjöblom. R., et al contributors. Decommissioning of research reactors and other small facilities by making optimal use of available resources. IAEA Report Series 463, Vienna 2008.

[15] Brundtland, G., Chairman, Our Common Future (The Brundtland report). World Commission on environment and Development, Oxford University Press, Oxford, United Kingdom, 1987.

[16] See OECD. 'Guiding Principles Concerning International Economic Aspects of Environmental Policies', Council Recommendation C(72)128, Paris, 26 May 1972.

[17] Charter of ethics. Four Pillars of Support for a Fast-Globalizing Nuclear Industry. World Nuclear Association brochure.

[18] Nuclear Energy in a Sustainable Development Perspective. OECD Nuclear Energy Agency, 2000, ISBN: 926418278X.

[19] Coal and sustainable development. A position paper by the Coal Industry Advisory Board prepared for the World Summit on Sustainable Development Johannesburg, OECD International Energy Agency. August 2002.

[20] Saaty, T. L., The analytic network process, Decision making with dependence and feedback. RWS Publications, Pittsburg, USA, 2001. ISBN 0962031798.

[21] Saaty, T. L. \& Vargas L. G., Decision making in economic, political, social and technological environments with the analytic hierarchy process. The analytic hierarchy process series Vol VII. RWS Publications, Pittsburg, USA, 1994. ISBN 0962031771.

[22] Petersen, D., Analyzing safety system effectiveness, 3rd edition. Van Nostrand Reinhold, 1996. ISBN 0442021801.

[23] Chapman, N. A. \& McKinley, I. G., The geological disposal of nuclear waste. John Wiley \& Sons, 1987. ISBN 0471912492.

[24] SKI (1996). SKI SITE-94 Deep Repository Performance Assessment Project. SKI* Report 96:36 (2 volumes).

[25] Andersson, J., Dverstorp, B., Sjöblom, R. \& Wingefors, S., The SKI repository performance assessment project SITE-94. International High Level Waste Management Conference, 1-5 May, 1995, Las Vegas, Nevada, U.S.A.

[26] Andersson, J., Editor, The joint SKI/SKB scenario development project. SKI* Technical Report 89:14, Stockholm, December 1989. (This report is also published as SKB Technical Report 89-35). 
[27] Stenhouse, M., Chapman, N. \& Sumerlin, T., SITE 94. Scenario Development. FEP audit list preparation: Methodology and presentation. SKI* Technical Report 93:27, Stockholm, April 1993.

[28] Chapman, N. S., Andersson, J., Robinson, P., Skagius, K., Wene, C-O., Wiborgh, M. \& Wingefors, S., Devising scenarios for future repository evolution: a rigorous methodology. Mat. Res. Soc. Symp. Proc. Vol. 353. Materials Research Society, 1995.

[29] Sjöblom, R., Dverstorp, B. \& Wingefors, S., Objectives and limitations of scientific studies with reference to the Swedish RD\&D Programme 1992 for handling and final disposal of nuclear waste. Mater. Res. Soc. Symp. Proc. Volume 333, Pittsburgh, PA 1994.

[30] Uranium 2009, Resources, Production and Demand. Jointly prepared by OECD, Nuclear Energy Agency and International Atomic Energy Agency (IAEA). OECD Publishing, 2010. ISBN: 9789264047891.

[31] Moberg, L., editor, The Chernobyl fallout in Sweden. Results from a research programme on environmental radiology. The Swedish Radiation Protection Institute, 1991. ISBN 9163007215.

[32] Arrhenius, S., Kemien och det moderna livet. Hugo Gebers Förlag, Stockholm, 1919. German translation: Die Chemie und das moderne Leben. Autoris. deutsche Ausgabe von B. Finkelstein. Lpz., Akadem. Vlgsanst., 1922. English translation: Chemistry in Modern Life. Translated from the Swedish and revised by Clifford Shattuck Leonard, New York, D. van Nostrand Co., 1925.

[33] The Swedish Environmental Code. English translation. Ds 2000:61. (In Swedish Miljöbalk, SFS 1998:808).

[34] Accounting Act. (In Swedish: Bokföringslag). SFS 1999:1078.

[35] Annual Reports Act. (In Swedish: Årsredovisningslag). SFS 1995:1554

[36] The Swedish Companies Act. (In Swedish: Aktiebolagslagen). SFS 2005:551.

[37] International Financial Reporting Standards and International Accounting Standards (IFRS/IAS). International Accounting Standards Board. 2008.

[38] The Swedish Penal Code. (In Swedish: Brottsbalk). SFS 1962:700.

[39] Standard Guide for Estimating Monetary Costs and Liabilities for Environmental Matters. ASTM Standard E 2137 - 06, December 2006.

[40] Standard Guide for Disclosure of Environmental Liabilities. ASTM Standard E 2173 - 07, April 2007.

[41] Padilla, E., Intergenerational equity and sustainability. Ecological Economics 41 (2002) 69-83.

* SKI $=$ Swedish Nuclear Power Inspectorate, now Swedish Radiation Safety Authority (SSM). Reports are available at www.ssm.se. 